\title{
Temporal trends and regional variation in the rate of arthroscopic knee surgery in England: analysis of over 1.7 million procedures between 1997 and 2017. Has practice changed in response to new evidence?
}

\author{
Simon G F Abram (1) , ${ }^{1}$ Andrew Judge, ${ }^{1,2}$ David J Beard, ${ }^{1}$ Hannah A Wilson, ${ }^{1}$ \\ Andrew J Price $^{1}$
}

- Additional material is published online only. To view please visit the journal online (http://dx.doi.org/10.1136/ bjsports-2018-099414).

${ }^{1}$ Nuffield Department of Orthopaedics, Rheumatology and Musculoskeletal Sciences, University of Oxford, Oxford, UK ${ }^{2}$ Musculoskeletal Research Unit, University of Bristol, Bristol, UK

\section{Correspondence to} Mr Simon G F Abram, Nuffield Department of Orthopaedics, Rheumatology and Musculoskeletal Sciences, University of Oxford, Oxford, OX3 7LD, UK:

simon.abram@ndorms.ox.ac.uk

Accepted 30 August 2018 Published Online First 2 October 2018
Check for updates

(C) Author(s) (or their employer(s)) 2019. No commercial re-use. See rights and permissions. Published by BMJ.

To cite: Abram SGF,

Judge A, Beard DJ,

et al. Br J Sports Med

2019:53:1533-1538.

\section{ABSTRACT}

Objectives We investigated trends and regional variation in the rate of arthroscopic knee surgery performed in England from 1997-1998 to 2016-2017. Design Cross-sectional study of the national hospital episode statistics (HES) for England.

Methods All hospital episodes for patients undergoing a knee arthroscopy between 1 April 1997 and 31 March 2017 were extracted from HES by procedure code. Age and sex-standardised rates of surgery were calculated using Office for National Statistic population data as the denominator. Trends in the rate of surgery were analysed by procedure both nationally and by Clinical Commissioning Group (CCG).

Results A total of 1088872 arthroscopic partial meniscectomies (APMs), 326600 diagnostic arthroscopies, 308618 knee washouts and 252885 chondroplasties were identified (1 759467 hospital admissions; 1447142 patients). The rate of APM increased from a low of $51 / 100000$ population $(95 \% \mathrm{Cl}$ 51 to 52) in 1997-1998 to a peak at 149/100 000 (95\% Cl 148 to 150) in 2013-2014; then, after 2014-2015, rates declined to $120 / 100000(95 \% \mathrm{Cl} 119$ to 121$)$ in 2016-2017. Rates of arthroscopic knee washout and diagnostic arthroscopy declined steadily from 50/100 $000(95 \% \mathrm{Cl} 49$ to 50) and 47/100 000 (95\% Cl 46 to 47) respectively in 1997-1998, to $4.8 / 100000$ (95\% $\mathrm{Cl} 4.6$ to 5.0$)$ and $8.1 / 100000(95 \% \mathrm{Cl} 7.9$ to 8.3$)$ in 2016-2017. Rates of chondroplasty have increased from a low of $3.2 / 100000(95 \% \mathrm{Cl} 3.0$ to 3.3) in 1997-1998 to $51 / 100000$ (95\% Cl 50.6 to 51.7) in 2016-2017. Substantial regional and age-group variation in practice was detected. In 2016-2017, between 11\% (22/207) and $16 \%$ (34/207) of CCGs performed at least double the national average rate of each procedure.

Conclusions Over the last 20 years, and likely in response to new evidence, rates of arthroscopic knee washout and diagnostic arthroscopy have declined by up to $90 \%$. APM rates increased about $130 \%$ overall but have declined recently. Rates of chondroplasty increased about 15-fold. There is significant variation in practice, but the appropriate population intervention rate for these procedures remains unknown.

\section{INTRODUCTION}

Of all musculoskeletal symptoms, knee pain is second only to back pain in terms of prevalence. ${ }^{1}$ One quarter of all people over the age of 55 experience persistent episodes of knee pain and around

\section{What are the findings?}

- Although the rate of knee washout and arthroscopic partial meniscectomy has declined in response to published high-level evidence, there is large variation in practice.

- Arthroscopic chondroplasty surgery is being performed increasingly frequently with currently only limited supporting evidence.

How might it impact on clinical practice in the near future?

The variation in intervention rates may drive more standardised clinical practice and the development of commissioning guidance.

- Measurement of the impact from improved treatment strategies on arthroscopic intervention rates and associated outcomes will be informed by comparison to the rates reported in this study.

one sixth of these people with knee pain consult their general practitioner each year. ${ }^{2}$ The prevalence of painful disabling knee osteoarthritis in people aged over 55 years is $10 \% .^{2}$ Meniscal pathology is also extremely common, with an overall prevalence of approximately $45 \%$ in patients over the age of 50 reporting knee pain, aching or stiffness. ${ }^{3}$

Historically, both osteoarthritis and meniscal pathology have been treated arthroscopically. ${ }^{4}$ Knee arthroscopy is the most commonly performed type of orthopaedic surgical intervention, worldwide. ${ }^{56}$ Over the last 20 years, a number of clinical trials have evaluated knee arthroscopy procedures, as summarised in table 1 (see also online supplementary appendix 1). For example, between 1997 and 2008, multiple trials demonstrated the ineffectiveness of joint washout for the treatment of advanced osteoarthritis. ${ }^{7-9}$ Some previous data suggest that rates of knee washout declined in response to this evidence. $^{1011}$ Two recent trials have compared mechanical debridement with radiofrequency 'chondroplasty' for the treatment of articular cartilage damage. ${ }^{12} 13$ The number of these procedures performed, and the trends in practice are, however, unknown. 


\begin{tabular}{|c|c|c|c|c|c|c|c|c|c|c|}
\hline & 1997/1998 & $1999 / 2000$ & $2001 / 2002$ & $2003 / 2004$ & $2005 / 2006$ & $2007 / 2008$ & $2009 / 2010$ & $2011 / 2012$ & $2013 / 2014$ & $2015 / 2016$ \\
\hline Lavage/washout & & 2 RCT & 2 RCT & 2 RCT & & $\begin{array}{l}1 \mathrm{RCT} \\
1 \mathrm{NG}\end{array}$ & $2 S R$ & & $1 \mathrm{NG}$ & $1 \mathrm{SR}$ \\
\hline APM & & & & & & $1 \mathrm{RCT}$ & & $1 \mathrm{RCT}$ & $\begin{array}{l}5 \mathrm{RCT} \\
1 \mathrm{SR}\end{array}$ & $\begin{array}{l}1 \mathrm{RCT} \\
3 \mathrm{SR}\end{array}$ \\
\hline Chondroplasty & & & $2 \mathrm{RCT}$ & & $1 \mathrm{RCT}$ & $1 \mathrm{RCT}$ & $1 \mathrm{RCT}$ & & $1 \mathrm{NG}$ & $1 S R$ \\
\hline
\end{tabular}

APM, arthroscopic partial meniscectomy; NG, National Institute for Health and Care Excellence guideline; RCT, randomised controlled clinical trial; SR, systematic review.

Meniscal tears may be managed surgically with either arthroscopic meniscal repair or excision (meniscectomy). ${ }^{14} 15$ Trials published between 2007 and 2016 challenged the effectiveness of arthroscopic partial meniscectomy (APM) to treat meniscal tears in many patients groups. ${ }^{16-23}$ This was concerning as arthroscopic knee surgery is not an entirely benign procedure and may be associated with rare but serious complications. ${ }^{24} 25$ In England, simple procedure count data suggested a rapid rise in the rate of arthroscopic knee surgery until at least $2012 .{ }^{24} 26$ However, all but one of the clinical trials evaluating APM was published since 2012, and the impact of this evidence on standardised rates of surgery in clinical practice is unknown. As a result, the current healthcare burden of this surgery is uncertain and, furthermore, an analysis of the geographical variation in the rate of surgery has not been performed. The knee arthroscopy intervention rate varies considerably between countries and regional variation in similar procedures, such as shoulder arthroscopy, has been reported previously. ${ }^{27-32}$

We aimed to determine the trend in the age and sexstandardised population intervention rate of arthroscopic knee surgery over a 20-year period from 1997 to 2017. Particular focus is given to the analysis of APM surgery, given the recently published evidence and because this is the most commonly performed procedure. Regional variation was explored by Clinical Commissioning Group (CCG).

\section{METHODS}

Hospital Episode Statistics (HES) data were obtained from National Health Service (NHS) Digital (application DARS-NIC-68703). The HES data contain a record of all attendances for NHS hospitals in England. ${ }^{33}$ The data are submitted by hospitals for payment for the services they provide and also intended for secondary use, including research. HES includes episodes of care delivered in treatment centres (including those in the independent sector) but funded by the NHS, episodes of care in England where patients are resident outside of England, and privately funded patients treated within NHS England hospitals. The information held in the HES database includes patient demographic and residence data, primary and secondary diagnoses and all procedures undertaken.

All HES records between 1 April 1997 and 31 March 2017 were extracted for patients undergoing: (1) APM, (2) diagnostic arthroscopy, (3) arthroscopic washout and (4) arthroscopic chondroplasty. Episodes were identified from the Classification of Surgical Operations and Procedures (OPCS-4) codes in the procedure fields within the HES data (see online supplementary appendix 2 for OPCS- 4 code list). ${ }^{34}$ Simultaneous procedures (ipsilateral or contralateral) were included.

To investigate geographical variation in practice, the CCG responsible for the episode of treatment was identified. In England, CCGs were created as part of the Health and Social Care Act 2012 and replaced Primary Care Trusts in April 2013. ${ }^{35}$ CCGs are the statutory bodies responsible for the planning and commissioning of all healthcare services for their local area. As of April 2017, there were 207 CCGs in England, and each is responsible for an average population of approximately 250000 (range 70000 to 900000 ). ${ }^{3536}$ Population data by age, gender and year within each CCG were obtained from the Office for National Statistics (ONS) and linked with the HES data for analysis.

\section{Statistical analysis}

Stata V.15.1 (StataCorp) was used to perform all analysis. Descriptive statistics were used to summarise the age and sex of patients undergoing each type of procedure. Population data from the ONS were used to calculate age and sex-standardised rates of intervention by year of treatment, following the methodology of the Association of Public Health Observatories. ${ }^{37}$ Annual trends were reported at procedure level (not mutually exclusive: including simultaneous ipsilateral or contralateral procedures). Overall trends in the number of hospital care episodes (patient admissions) were determined. In accordance with ONS and NHS Digital guidance, rates where the number of events was less than six were suppressed. ${ }^{38}$ The geographic information system, QGIS V.2.99 (qgis.org), was used to graphically summarise age and sex-standardised rates for each CCG, per year. Standardised CCG level data were determined for all episodes and mapped using the April 2017 boundaries for consistency over time. ${ }^{39}$

\section{Patient and public involvement}

The study was supported by a patient advisory group which provided input into a programme of research, including this study, prior to commencement.

\section{RESULTS}

Between 1 April 1997 and 31 March 2017, a total of 1088872 APMs, 326600 diagnostic knee arthroscopies, 308618 washout procedures and 252885 chondroplasties were performed. This was a total of 1976975 procedures (1 759467 hospital admissions) in 1447142 patients. A summary of the patient demographics for each procedure is shown in table 2 .

\section{National trends}

Figure 1 summarises the trends in the age-sex-standardised rate of surgery per 100000 population for each of type of arthroscopic procedure. Overall, the number of procedures increased $22 \%$ from $151 / 100000$ (95\% CI 150 to 152) in 1997 1998 to $184 / 100000$ (95\% CI 183 to 185 ) in 2016/2017, and the number of hospital admissions for knee arthroscopy increased $9 \%$ from $137 / 100000$ (95\% CI 135 to 138 ) to $149 / 100000$ (95\% CI 148 to 150$)$.

\section{Arthroscopic partial meniscectomy}

The rate of APM increased from a low of 51/100 000 population (95\% CI 51 to 52 ) in $1997-1998$ to $92 / 100000$ (95\% CI 91 
Table 2 Patient demographics by procedure type

\begin{tabular}{|c|c|c|c|c|}
\hline & Procedures (n) & Patients (n) & Women & Mean age (SD) \\
\hline Arthroscopic partial meniscectomy & 1088872 & 938612 & $425126(45.3 \%)$ & $48.7(15.1)$ \\
\hline Diagnostic & 326600 & 305823 & $138210(45.2 \%)$ & $43.1(17.1)$ \\
\hline Washout & 308618 & 286127 & $122516(42.8 \%)$ & $50.4(17.5)$ \\
\hline Chondroplasty & 252885 & 233594 & $107456(46.0 \%)$ & $49.9(14.1)$ \\
\hline
\end{tabular}

to 93 ) in 2006-2007, before increasing rapidly then plateauing between 2010 and 2015, with a peak at 149/100 000 (95\% CI 148 to 150 ) in 2013-2014 (figure 1). Rates then declined to $120 / 100000$ (95\% CI 119 to 121) in 2016-2017. Figure 2 summarises the trend in the rate of APM surgery over time by age group. The greatest increase in the rate of surgery was seen in the 40-59 and 60-79 age groups between 1997-1998 and 2013-2014. This trend reversed after 2013-2014, and a decline in the rate of APM in these age groups has been observed to 2016-2017.

\section{Arthroscopic knee washout, diagnostic arthroscopy}

Rates of arthroscopic knee washout and diagnostic arthroscopy declined from 50/100 000 (95\% CI 49 to 50) and 47/100 000 (95\% CI 46 to 47 ) respectively in 1997-1998, to $4.8 / 100000$ (95\% CI 4.6 to 5.0$)$ and 8.1/100 000 (95\% CI 7.9 to 8.3 ) respectively in 2016-2017 (figure 1). Age-group trends are available in the supplementary appendix (online supplementary appendix 3).

\section{Arthroscopic chondroplasty}

Rates of chondroplasty increased steadily from a low of $3.2 / 100000$ (95\% CI 3.0 to 3.3) in $1997-1998$ to $51 / 100000$ (95\% CI 51 to 52) in 2016-2017 (figure 1). Age-group trends

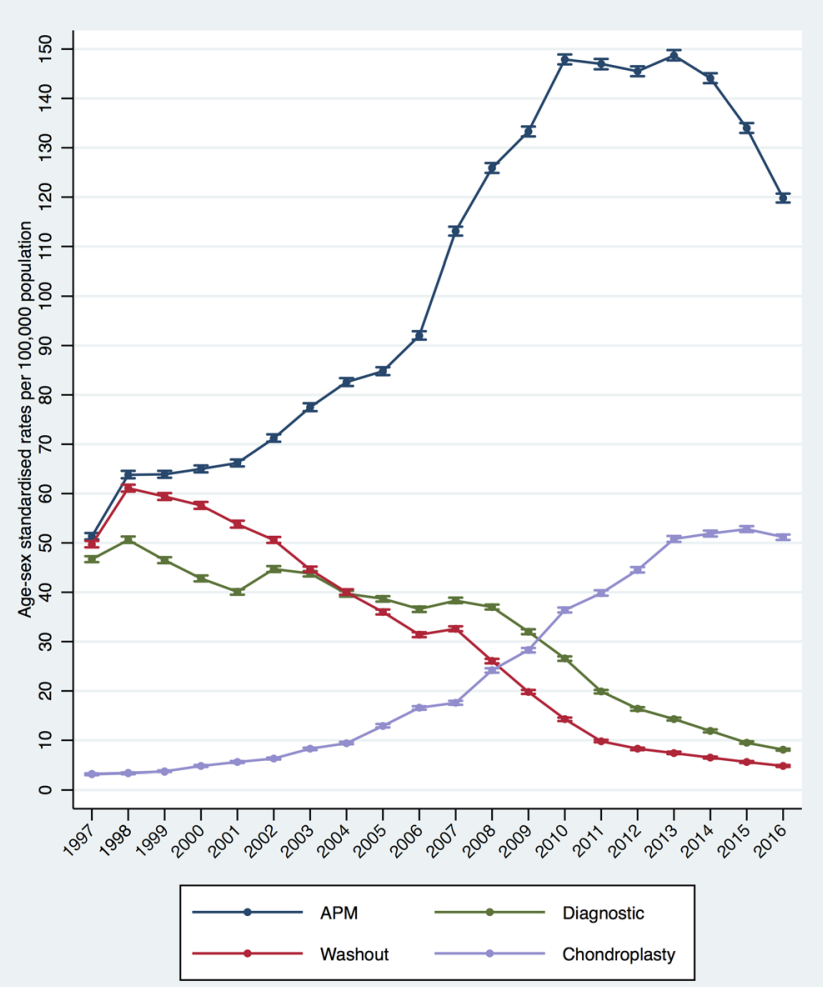

Figure 1 Age-sex-standardised rates of arthroscopic procedures per 100000 population. APM, arthroscopic partial meniscectomy. are available in the supplementary appendix (online supplementary appendix 3).

\section{Variation by CCG}

Geographical variation by CCG in the age-sex-standardised rate of APM over time is summarised in figure 3 . There was a striking, near 10 -fold, variation in the rate of surgery between CCGs for APM and all the other procedures evaluated (figure 4; see also online supplementary appendix 3 ). In contrast to the overall declining national trend in APM, many CCGs performed surgery at an increasing rate or unchanged rate in recent years. Between 2015-2016 and 2016-2017, the rate of APM performed increased by at least 5\% in 25\% (52/207) of CCGs (online supplementary appendix 3).

In 2016-2017, 22 CCGs (10.6\%) performed more than double the national average rate of APM, while in the same year, 15 CCGs (7.2\%) performed less than $10 \%$ of the national average rate (figure 4). For chondroplasty, 12 CCGs $(5.8 \%)$ performed less than $10 \%$ of the national average, whereas 30 CCGs $(14.5 \%)$ performed at least double the national average rate. For washout/lavage, 62 CCGs (30.0\%) performed less than $10 \%$ of the national average, whereas 32 CCGs $(15.5 \%)$ performed at least double the national average rate. For diagnostic arthroscopy, 42 CCGs (20.3\%) performed less than $10 \%$

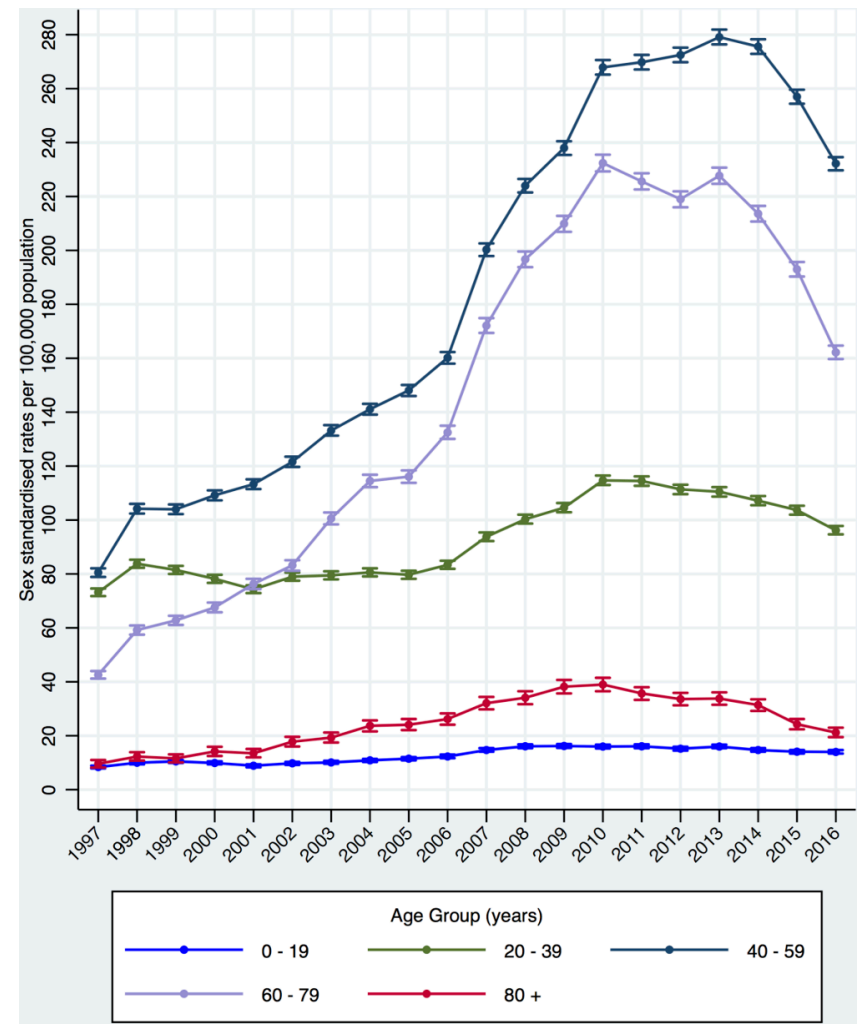

Figure 2 Sex-standardised rate of APM per 100000 population by age group and year. APM, arthroscopic partial meniscectomy. 


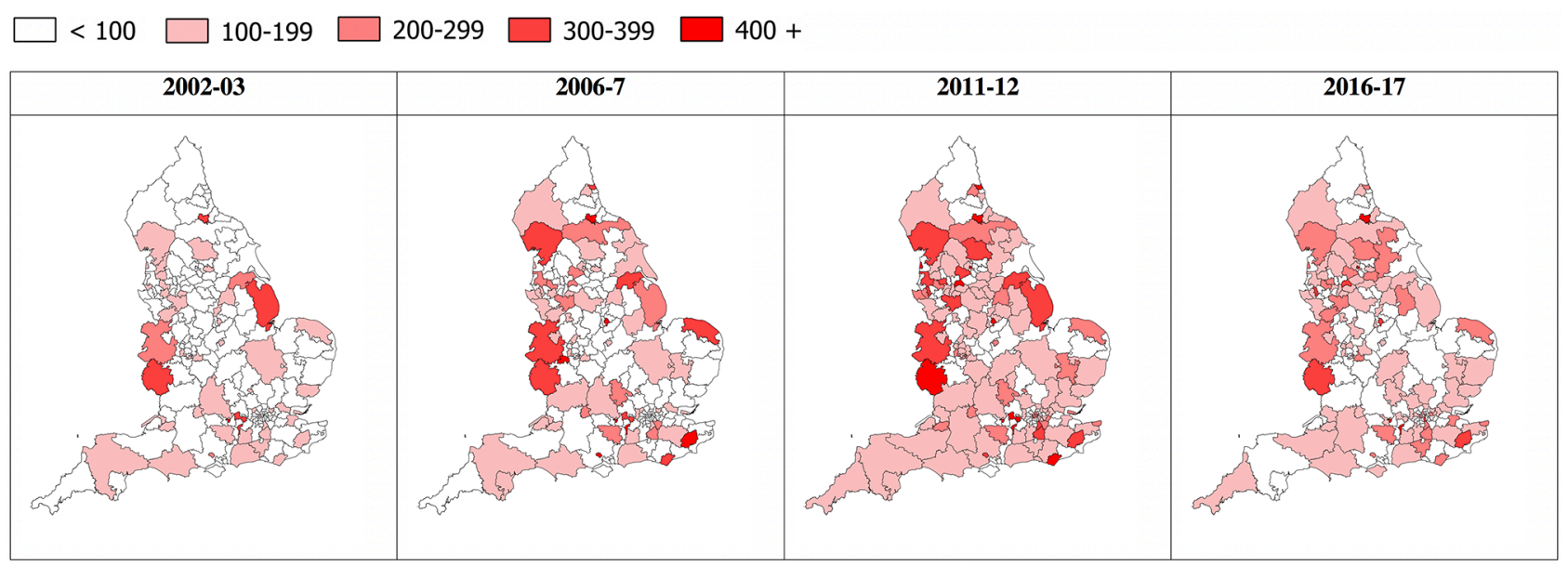

Figure 3 Regional variation in age-sex-standardised rate of arthroscopic partial meniscectomy per 100000 population by National Health Service Clinical Commissioning Group.

of the national average, whereas 34 CCGs (16.4\%) performed at least double the national average rate.

\section{DISCUSSION}

This study of over 1.7 million hospital episodes indicates that there has been a dramatic change in the practice of arthroscopic knee surgery over the last 20 years and, within these trends, there is considerable geographical variation in practice.

\section{National trends}

The rate of APM surgery increased by $190 \%$ from 51 per 100000 in $1997-1998$ to 149 per 100000 in 2013-2014, before declining to 120 per 100000 in 2016-2017. In contrast, a consistent decline in the rate of arthroscopic washout procedures was observed-in line with published clinical trial evidence challenging the efficacy of arthroscopic washout and debridement for osteoarthritis between 1993 and 2008, and National Institute for Health and Care Excellence (NICE) guidance published in 2007 (table 1). ${ }^{784041}$ A similar decline in the rate of diagnostic knee arthroscopy was noted over the 20-year study period. This may reflect increased adoption of MRI as the diagnostic modality of choice for the knee. ${ }^{42} 43$

Rates of chondroplasty procedures including abrasion and radiofrequency chondroplasty have increased steadily by a total of $1500 \%$ from 3.2 per 100000 in $1997-1998$ to 51 per 100000 in 2016-2017. NICE guidance issued in May 2014 was cautiously supportive of radiofrequency chondroplasty for discrete chondral defects of the knee, based on clinical trials comparing radiofrequency chondroplasty with mechanical debridement (table 1). ${ }^{13}{ }^{44-46}$ The increase in the rate of chondroplasty has, however, occurred in the absence of highquality controlled trials comparing the intervention to either

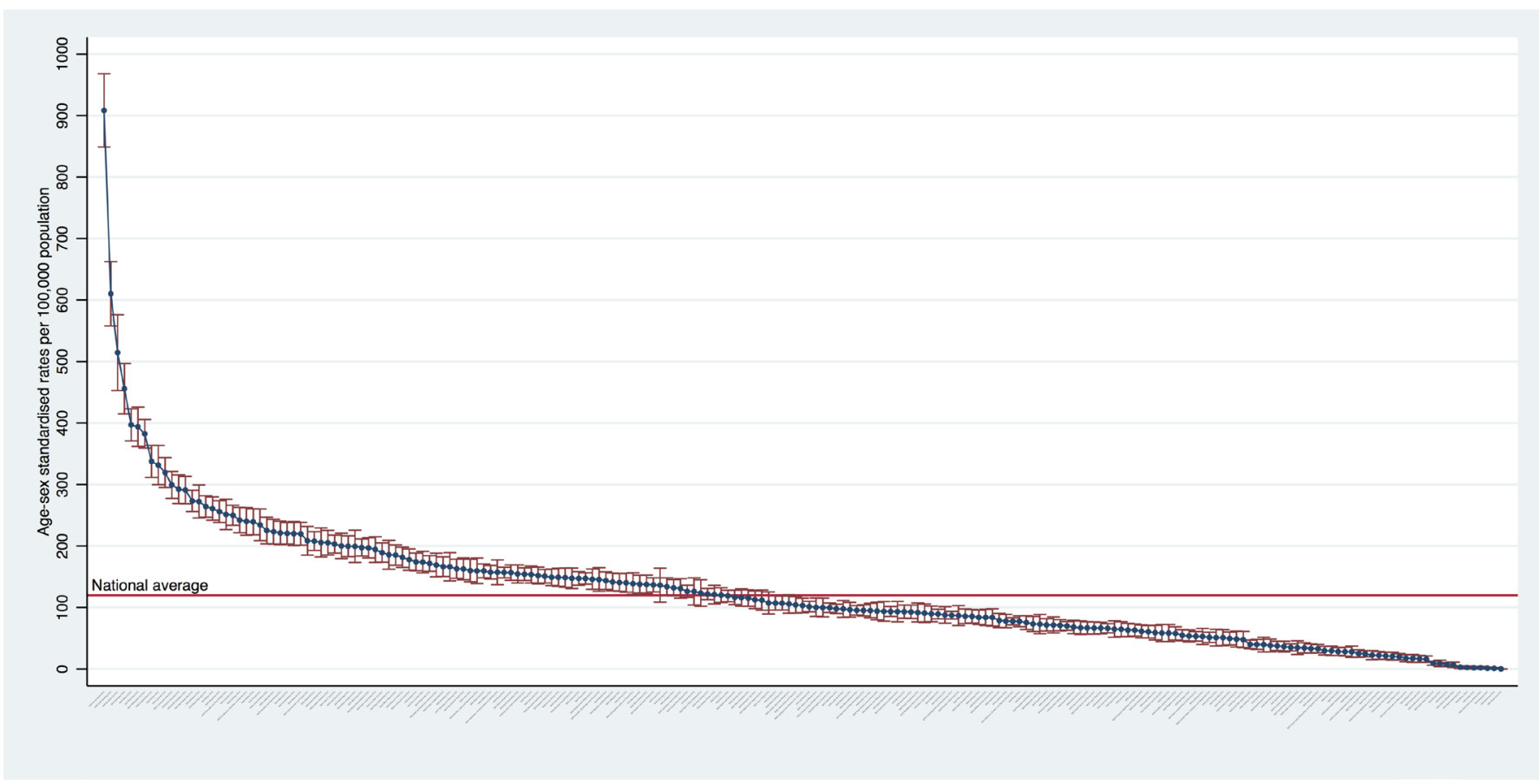

Figure 4 Plot summarising the variation in the rate of arthroscopic partial meniscectomy per 100000 population by National Health Service Clinical Commissioning Group in 2016-2017. 
a non-operative or placebo surgical comparator, or evaluating treatment in patients with non-discrete lesions. More evidence is required to determine the efficacy of this procedure and should be a priority for further research.

For APM, a large increase in the rate of surgery over time was noted in older age groups, 40-59 and 60-79, followed by a partial decline. Eight randomised controlled clinical trials of APM have been published between 2007 and 2016. ${ }^{16-23}$ The decline was particularly evident since the publication of five of the eight trials in 2012-2013. These trials challenged the efficacy of the procedure, predominantly in older patients with degenerative knee disease; our study demonstrates some change in practice coincident with this evidence.

\section{Variation by CCG}

Although, there has been an overall decrease in the number of knee arthroscopy procedures performed in England in recent years, our findings show that there is considerable variation in this trend across CCGs. On average, 14\% of CCGs were performing at least double the national average rate of these procedures in 2016-2017. Factors underlying such regional variation have been previously investigated. ${ }^{47}$ CCGs with considerably higher rates of APM may have a greater number of specialist surgeons with greater belief in the efficacy of the procedure, greater availability of hospital resources such as appropriate day case theatre time or the variation may reflect patient treatment choices-both regarding surgery versus alternative treatment options and also the ability of patients to choose their treating hospital.

Variation in knee arthroscopy intervention rates has been reported internationally. In the USA in 2006, a knee arthroscopy intervention rate of approximately 400 per 100000 population was reported. ${ }^{27}$ In 2012, the rate of knee arthroscopy in Scotland was around 120 per 100000 in patients over the age of 60 , and this rate remained relatively stable between 2000 and $2013 .^{28}$ To 2012, rates of arthroscopic meniscal surgery in Finland were approximately 125 per 100 000; yet the same study found the equivalent rate in Sweden was less than 50 per $100000 .{ }^{29}$ In Canada, a rate of approximately 180 per 100000 was reported in $2004 .{ }^{30}$ In Australia, a relatively stable rate of knee arthroscopy was reported from 2001 to 2008 at just under 350 per $100000 .{ }^{31}$ Comparison of data reported by studies from other countries is, however, limited by differing reporting years, variation in the procedures included and coding practices and the inclusion or exclusion of patients treated in private hospitals.

Overall, in this study, the total number of procedures increased by $22 \%$ and the number of hospital episodes by $9 \%$ from 1997 to 1998 to 2016-2017. Perhaps the greatest challenge to the interpretation of these findings is that the 'appropriate' intervention rate for the population is unknown. For example, for APM, in response to the clinical trial evidence, several clinical guidelines have been produced. ${ }^{26} 4849$ The number of patients presenting annually meeting the clinical and radiological criteria representing surgical 'candidacy' according to these guidelines is, however, unknown. Further work is required in this area, considering the indications applied, patient preferences, an evaluation of risks and an assessment of the associated rates of undesirable outcomes such as subsequent knee arthroplasty.

\section{Strengths and limitations}

This study has been performed using the most comprehensive and complete hospital episode dataset for England. All hospital episodes of NHS patients (including those treated in the independent sector) over a 20-year period were included. The population intervention rates reported in this study will, however, be an underestimate of the true population rate as private patient data are not available unless these patients were treated in NHS hospitals. Although the proportion of arthroscopic procedures performed in the private sector over time is unknown, national data does indicate that private healthcare expenditure as a proportion of total healthcare expenditure has remained relatively stable. ${ }^{50}$ For example, between 2005 and 2015, private expenditure increased just $1 \%$ from $17 \%$ of total expenditure to $18 \% .^{50}$

A further potential limitation is the reliance on accurate data coding. For this study, surgical procedure codes were analysed, and the direct linkage of these data to hospital remuneration provides a strong incentive for hospitals to accurately record this information. It remains possible, however, that some of the apparent change in the number of procedures being performed may reflect a change in coding practice rather than a real change in practice. This is a potential limitation of all large health database studies, however, given the importance of HES data records for reimbursement of hospital care costs and the anticipated impact from emerging clinical trial evidence and new guidelines issued, we believe a change in coding practice is unlikely to be the main cause of the trends observed.

Geographical variation data were available from 2002 and configured to the CCG boundaries as on 1 April 2017 for consistency over time. In interpreting these data, we note that CCGs only replaced the previous primary care trusts in April 2013 and that not all CCG regions include a hospital that performs arthroscopic surgery. The regional rates of surgery are adjusted by the age and sex of the regional population, but patient migration and other geographical factors may underlie the reported variation. The purpose of this study was not, however, to determine the cause of variation but simply to report and discuss this variation and the associated trends in practice over time.

\section{CONCLUSION}

We believe the significant change in surgical practice likely represents a response, in part, to the publication of clinical trial evidence and guidelines, particularly applicable to the practice of knee washout and APM. There remains wide geographical variation in practice, and the rate of arthroscopic chondroplasty has increased substantially without high-quality supporting evidence. For all types of arthroscopic knee surgery, the 'appropriate' population intervention rate that maximises the clinical and cost effectiveness of these procedures is currently unknown and must be a priority for future research.

Contributors SGFA: guarantor, concept, methodology, analysis, writing and editing paper. AJ: methodology, writing and editing paper. DJB: concept, writing and editing paper. HAW: writing and editing paper. AJP: concept, methodology, writing and editing paper.

Funding This report is independent research supported by the National Institute for Health Research (NIHR Doctoral Research Fellowship, Mr Simon Abram, DRF2017-10-030) and National Institute for Health Research (NIHR) Oxford Biomedical Research Centre (BRC).

Disclaimer The views expressed in this publication are those of the authors and not necessarily those of the NHS, the National Institute for Health Research or the Department of Health.

Competing interests All authors have completed the Unified Competing Interest form (available on request from the corresponding author). Andrew Judge has received consultancy fees from Freshfields Bruckhaus Deringer (on behalf of Smith \& Nephew Orthopaedics Limited) and is a member of the Data Safety and Monitoring 
Board (which involved receipt of fees) from Anthera Pharmaceuticals, Inc. All other authors declare: no support from any organisation for the submitted work; no financial relationships with any organisations that might have an interest in the submitted work in the previous three years, no other relationships or activities that could appear to have influenced the submitted work.

Patient consent Not required.

Provenance and peer review Not commissioned; externally peer reviewed.

Data sharing statement No additional data available.

ORCID ID

Simon G F Abram http://orcid.org/0000-0002-4452-6499

\section{REFERENCES}

1 Urwin M, Symmons D, Allison T, et al. Estimating the burden of musculoskeletal disorders in the community: the comparative prevalence of symptoms at different anatomical sites, and the relation to social deprivation. Ann Rheum Dis 1998;57:649-55.

2 Peat G, McCarney R, Croft P. Knee pain and osteoarthritis in older adults: a review of community burden and current use of primary health care. Ann Rheum Dis 2001;60:91-7.

3 Englund M, Guermazi A, Gale D, et al. Incidental meniscal findings on knee MRI in middle-aged and elderly persons. N Engl J Med 2008;359:1108-15.

4 Lohmander LS, Thorlund JB, Roos EM. Routine knee arthroscopic surgery for the painful knee in middle-aged and old patients--time to abandon ship. Acta Orthop 2016;87:2-4

5 Katz JN, Martin SD. Meniscus--friend or foe: epidemiologic observations and surgical implications. Arthritis Rheum 2009;60:633-5.

6 Järvinen TLN, Guyatt GH. Arthroscopic surgery for knee pain. BMJ 2016;3934:i3934.

7 Kirkley A, Birmingham TB, Litchfield RB, et al. A randomized trial of arthroscopic surgery for osteoarthritis of the knee. N Engl J Med 2008;359:1097-107.

8 Moseley JB, O'Malley K, Petersen NJ, et al. A controlled trial of arthroscopic surgery for osteoarthritis of the knee. N Engl J Med 2002;347:81-8.

9 Aaron RK, Skolnick AH, Reinert SE, et al. Arthroscopic débridement for osteoarthritis of the knee. J Bone Jt Surg 2006;88:936-43.

10 Amin NH, Hussain W, Ryan J, et al. Changes within clinical practice after a randomized controlled trial of knee arthroscopy for Osteoarthritis. Orthop J Sports Med 2017;5:1.

11 Lazic S, Boughton 0, Hing C, et al. Arthroscopic washout of the knee: a procedure in decline. Knee 2014;21:631-4.

12 Dandy DJ. Abrasion chondroplasty. Arthroscopy 1986;2:51-3.

13 Spahn G, Kahl E, Mückley T, et al. Arthroscopic knee chondroplasty using a bipolar radiofrequency-based device compared to mechanical shaver: results of a prospective, randomized, controlled study. Knee Surg Sports Traumatol Arthrosc 2008;16:565-73.

14 Monk P, Garfjeld Roberts P, Palmer AJR, et al. The urgent need for evidence in arthroscopic meniscal surgery: a systematic review of the evidence for operative management of meniscal tears. Am J Sports Med 2017;45:965-73.

15 Bryceland JK, Powell AJ, Nunn T, et al. Knee Menisci. Cartilage 2017;8:99-104.

16 Katz JN, Brophy RH, Chaisson CE, et al. Surgery versus physical therapy for a meniscal tear and osteoarthritis. N Engl J Med 2013;368:1675-84.

17 Sihvonen R, Paavola M, Malmivaara A, et al. Arthroscopic partial meniscectomy versus sham surgery for a degenerative meniscal tear. N Engl J Med 2013;369:2515-24.

18 Kise NJ, Risberg MA, Stensrud S, et al. Exercise therapy versus arthroscopic partial meniscectomy for degenerative meniscal tear in middle aged patients: randomised controlled trial with two year follow-up. BMJ 2016;354:i3740.

19 Gauffin H, Tagesson S, Meunier A, et al. Knee arthroscopic surgery is beneficial to middle-aged patients with meniscal symptoms: a prospective, randomised, singleblinded study. Osteoarthr Cartil 2014;22:1808-16.

20 Herrlin S, Hållander M, Wange P, et al. Arthroscopic or conservative treatment of degenerative medial meniscal tears: a prospective randomised trial. Knee Surgery, Sport Traumatol Arthrosc 2007;15:393-401.

21 Vermesan D, Prejbeanu R, Laitin S, et al. Arthroscopic debridement compared to intra-articular steroids in treating degenerative medial meniscal tears. Eur Rev Med Pharmacol Sci 2013;17:3192-6.

22 Yim JH, Seon JK, Song EK, et al. A comparative study of meniscectomy and nonoperative treatment for degenerative horizontal tears of the medial meniscus. Am J Sports Med 2013;41:1565-70.

23 Østerås H, Østerås B, Torstensen TA. Medical exercise therapy, and not arthroscopic surgery, resulted in decreased depression and anxiety in patients with degenerative meniscus injury. J Bodyw Mov Ther 2012;16:456-63.

24 Jameson SS, Dowen D, James P, et al. The burden of arthroscopy of the knee: a contemporary analysis of data from the English NHS. J Bone Joint Surg $\mathrm{Br}$ 2011;93:1327-33.
25 Thorlund JB, Juhl CB, Roos EM, et al. Arthroscopic surgery for degenerative knee: systematic review and meta-analysis of benefits and harms. BMJ 2015;350:h2747.

26 Siemieniuk RAC, Harris IA, Agoritsas T, et al. Arthroscopic surgery for degenerative knee arthritis and meniscal tears: a clinical practice guideline. BMJ 2017;357:j1982.

27 Kim S, Bosque J, Meehan JP, et al. Increase in outpatient knee arthroscopy in the United States: a comparison of national surveys of ambulatory surgery, 1996 and 2006. J Bone Joint Surg Am 2011;93:994-1000.

28 Hamilton DF, Howie CR. Knee arthroscopy: influence of systems for delivering healthcare on procedure rates. BMJ 2015;351:h4720-4.

29 Mattila VM, Sihvonen R, Paloneva J, et al. Changes in rates of arthroscopy due to degenerative knee disease and traumatic meniscal tears in Finland and Sweden. Acta Orthop 2016;87:5-11.

30 Hawker G, Guan J, Judge A, et al. Knee arthroscopy in England and Ontario: patterns of use, changes over time, and relationship to total knee replacement. J Bone Joint Surg Am 2008;90:2337-45.

31 Harris IA, Madan NS, Naylor JM, et al. Trends in knee arthroscopy and subsequent arthroplasty in an Australian population: a retrospective cohort study. BMC Musculoskelet Disord 2013;14:1-6.

32 Judge A, Murphy RJ, Maxwell R, et al. Temporal trends and geographical variation in the use of subacromial decompression and rotator cuff repair of the shoulder in England. Bone Joint J 2014;96-B:70-4.

33 NHS Digital. Hospital Episode Statistics. http://content.digital.nhs.uk/hes (accessed 4 Dec 2017).

34 NHS Digital. National clinical coding standards: OPCS-4 (2017): Stationery Office 2017.

35 NHS Clinical Commissioners. About CCGs. https://www.nhscc.org/ccgs/ (accessed 4 Dec 2017).

36 Clinical Commissioning Groups, 2017. Names and Codes in England (Version 3). https://data.gov.uk/dataset/clinical-commissioning-groups-april-2017-names-andcodes-in-england-version-31 (accessed 4 Dec 2017).

37 APHO, 2010. Commonly used public health statistics and their confidence intervals. https://fingertips.phe.org.uk/profile/guidance

38 NHS Digital, 2015. Hospital Episode Statistics (HES) analysis guide. http://content digital.nhs.uk/media/1592/HES-analysis-guide/pdf/HES_Analysis_Guide_March_ 2015.pdf (accessed 4 Dec 2017).

39 Office for National Statistics. Clinical Commissioning Groups (April 2017) Boundaries (Version 4). http://geoportal.statistics.gov.uk/ (accessed 4 Dec 2017).

40 Chang RW, Falconer J, Stulberg SD, et al. A randomized, controlled trial of arthroscopic surgery versus closed-needle joint lavage for patients with osteoarthritis of the knee. Arthritis Rheum 1993;36:289-96.

41 National Institute for Health and Care Excellence. Arthroscopic knee washout, with or without debridement, for the treatment of osteoarthritis (IPG230): NICE, 2007. (accessed 8 Jan 2018).

42 DAMASK (Direct Access to Magnetic Resonance Imaging: Assessment for Suspect Knees) Trial Team. Cost-effectiveness of magnetic resonance imaging of the knee for patients presenting in primary care. Br J Gen Pract 2008:58:10-16.

43 Solomon DH, Katz JN, Carrino JA, et al. Trends in knee magnetic resonance imaging Med Care 2003:41:687-92.

44 Spahn G, Klinger HM, Mückley T, et al. Four-year results from a randomized controlled study of knee chondroplasty with concomitant medial meniscectomy: mechanical debridement versus radiofrequency chondroplasty. Arthrosc J Arthrosc Relat Surg 2010;26:S73-S80.

45 Spahn G, Hofmann GO, von Engelhardt LV. Mechanical debridement versus radiofrequency in knee chondroplasty with concomitant medial meniscectomy: 10year results from a randomized controlled study. Knee Surg Sports Traumatol Arthrosc 2016;24:1560-8

46 National Institute for Health and Care Excellence (NICE). Arthroscopic radiofrequency chondroplasty for discrete chondral defects of the knee Guidance and guidelines: NICE, 2014. (accessed 10 Jan 2018).

47 Birkmeyer JD, Reames BN, McCulloch P, et al. Understanding of regional variation in the use of surgery. Lancet 2013;382:1121-9.

48 Beaufils P, Becker R, Kopf $S$, et al. Surgical management of degenerative meniscus lesions: the 2016 ESSKA meniscus consensus. Knee Surgery, Sport Traumatol Arthrosc 2017:25:335-46.

49 Stone JA, Salzler MJ, Parker DA, et al. Degenerative meniscus tears - assimilation of evidence and consensus statements across three continents: state of the art. I ISAKOS Jt Disord Orthop Sport Med 2017;2:108-19.

50 UK Health Accounts, 2016. Office for National Statistics. https://www.ons.gov.uk/ peoplepopulationandcommunity/healthandsocialcare/healthcaresystem/bulletins/ ukhealthaccounts/2016 (accessed 5 Jun 2018).

51 Murray CJ, Vos T, Lozano R, et al. Disability-adjusted life years (DALYs) for 291 diseases and injuries in 21 regions, 1990-2010: a systematic analysis for the Global Burden of Disease Study 2010. Lancet 2012;380:2197-223. 